Original Research

\title{
Assessment of occupational violence towards pharmacists at practice settings in Nigeria
}

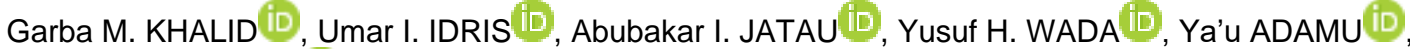 \\ Marzug A. UNGOGO iD. \\ Received (first version): 11-Jul-2020 Accepted: 11-Oct-2020 Published online: 19-Oct-2020
}

\begin{abstract}
Background: Occupational Violence is prevalent among healthcare workers, including pharmacists, and poses a big threat to their job satisfaction, safety, and social wellbeing.

Objective: This study seeks to assess the incidents and factors associated with occupational violence towards pharmacists in Nigeria. Methods: A cross-sectional study was conducted among pharmacists practicing in Nigeria, using an online survey (Google Form ${ }^{\mathrm{TM}}$ ). Occupational violence was assessed using a validated questionnaire. The survey was conducted and reported based on the Checklist for Reporting Results of Internet E-Surveys (CHERRIES). Participants were recruited by sharing the survey link via social media platforms including WhatsApp, Facebook, Linkedln, and Twitter.

Results: A total of 263 respondents returned the online questionnaire, with a completion rate of $99.2 \%$. The prevalence of occupational violence was $92.7 \%$ ( $95 \% \mathrm{Cl}, 90$ to 96$)$. Violent events occurred among $48.7 \%$ of pharmacists with at least six years of experience, and $68.4 \%$ of hospital pharmacists. The commonly reported factors associated with the violence include long waiting times in the pharmacy (36.5\%), refusal to fulfil aggressor's demands (22.1\%), and counseling/poor communication (21.7\%). Events related to verbal abuse were reported among $95 \%$ of the participants. The prevalence of violence was significantly higher among hospital pharmacists, compared with those practicing in administration/regulatory, and in community pharmacies (chi-square=10.213 (2); $p=0.006$ ). Similarly, physical aggression was higher among hospital pharmacists (chi-square $=10.646(2), p=0.005$ ).

Conclusions: The prevalence of occupational violence towards pharmacists practicing in Nigeria appeared to be high. Major factors associated with the violence were refusal to fulfil aggressors' demands and frustrations due to long waiting times at pharmacy. Recommended strategies to slowdown the incidences of violence were improved pharmacists' workforce, interprofessional harmony, and penalties against perpetrators.
\end{abstract}

Keywords

Pharmacists; Pharmacies; Workplace Violence; Aggression; Incidence; Job Satisfaction; Waiting Lists; Cross-Sectional Studies; Nigeria

\section{INTRODUCTION}

Pharmacists are among the key drivers of the healthcare system. Perhaps, due to their unique position in healthcare settings, pharmacists have been ranked as the most trusted and the most accessible healthcare professionals. ${ }^{1}$ Moreover, with advances in personalized medicine, pharmacogenomics, pharmacoepidemiology, pharmaceutical and information technology, new opportunities become available for pharmacists to improve their practice and science accordingly. Indeed, pharmacists' new roles in primary healthcare and other evolving platforms can enhance patient access to quality pharmaceutical care. ${ }^{2,3}$ Pharmacists practice in a broad multidisciplinary area including academia, regulatory, administrative, pharmaceutical industry, community pharmacy practice, and hospital or clinical pharmacy practice. Certainly, clinical pharmacists represent a set of

\footnotetext{
Garba M. KHALID. BPharm, MSc. Faculty of Pharmaceutical Sciences, Bayero University. Kano, (Nigeria). khalidgmk@gmail.com Umar I. IDRIS. BPharm, MSc. Faculty of Pharmaceutical Sciences, Bayero University. Kano, (Nigeria).rxumar@gmail.com Abubakar I. JATAU. BPharm, MSc. School of Pharmacy and Pharmacology, University of Tasmania. Hobart, TAS, (Australia). pharmjt@gmail.com

Yusuf H. WADA. BPharm. Faculty of Pharmaceutical Sciences, Usmanu Danfodiyo University Sokoto. (Nigeria). hasawa2011@gmail.com

Ya'u ADAMU. BPharm, MSc. Faculty of Pharmaceutical Sciences,

Bayero University. Kano, (Nigeria). yabal2004@gmail.com

Marzuq A. UNGOGO. DVM, MSc. Department of Veterinary

Pharmacology and Toxicology, Ahmadu Bello University. Zaria,

(Nigeria). myzooq@gmail.com
}

professionals best entrusted with all aspects of pharmacotherapy. By and large, the success of any therapeutic intervention depends largely on its safety, efficacy, appropriate dosage regimen, as well as the clinical pharmacist's competence and commitment. This includes guidance on appropriate and rational medicine use, as well as efforts in preventing adverse drug events. In addition, pharmacists ensure quality, effectiveness, and appropriate storage conditions of medications in healthcare facilities, and are actively involved in screening prescriptions for potential error and to suggest appropriate deprescription options. $^{4-6}$

Nigeria has a population of over 190 million people. ${ }^{7}$ A 2018 survey has revealed that out of the total number of 21,892 registered pharmacists in the country, only 12,807 are in active professional service. ${ }^{8}$ Thus, the pharmacist to population ratio was stagnating around 0.53 to 0.66 per 10,000 people, which is far below the density recommended by the World Health Organization (WHO)., The WHO has identified healthcare workers to be at high risk of violence all over the world. Consequently, $8 \%$ to $38 \%$ of health workers suffer physical violence at some point in their careers globally. In most cases, health workers are threatened or exposed to verbal aggression perpetrated by patients or visitors. ${ }^{10}$ Four types of workplace violence have been identified based on the motives and behaviors of the perpetrator: Type I, which involves criminal activity, and the perpetrator is a thief, shoplifter, or other non-client of the business; Type II, where the perpetrator is a client, 
customer, inmate, or patient; Type III, involved with an assault on an employee by another employee; and Type IV, that involved a personal, non-business acquaintance of the employee. ${ }^{11}$ Type II violence, perpetrated by a customer receiving services from an establishment, is the most common occupational violence faced by healthcare workers. ${ }^{11,12}$ Harassment, physical attack, physical threat, and verbal abuse are sub-types of Type II violence mainly used to define the nature of violent events perpetrated by patients and visitors. ${ }^{12}$ The healthcare workers most at risk of occupational violence include physicians, nurses, emergency room staff, and paramedics. ${ }^{12-14}$ Occupational violence towards pharmacists in the hospital and community pharmacy-based settings has been reported in many countries. ${ }^{12,15}$ However, despite its prevalence and daunting nature, peer-reviewed literature on the violence towards pharmacists in healthcare and other practice settings in Nigeria is lacking. Therefore, this study aims to estimate the prevalence and nature of occupational violence towards pharmacists in Nigeria, to determine factors associated with the violence, to identify the pharmacists at high risk, and to propose measures to curtail this menace.

\section{METHODS}

\section{Study design and population}

A cross-sectional study in the form of an online survey (Google Form ${ }^{\mathrm{TM}}$ ) was designed with the target population being pharmacists who are practicing in Nigeria. All fully qualified pharmacists with any social media account, such as Facebook, WhatsApp ${ }^{\mathrm{TM}}$, LinkedIn ${ }^{\mathrm{TM}}$ and Twitter $^{\mathrm{TM}}$ were eligible. Pharmacists who are on internship training were excluded from the study.

Due to the paucity of previous data on occupational violence towards pharmacists in Nigeria, we used a $91 \%$ expected prevalence rate $(p)$ to determine the minimum sample size $(n)$, based on a similar study among community pharmacists in Australia. ${ }^{16}$ Assuming $95 \%$ confidence interval, and a precision $(\Delta)$ of $0.5 \%$ and $z$ value of 1.96 , a sample size of 246 was determined using a single proportion formula, based on the following equation. ${ }^{16,17}$

$$
n=\left(\frac{z}{\Delta}\right)^{2} p(1-p)
$$

\section{Recruitment}

Eligible participants were invited to participate in the online survey using social media platforms including Facebook, WhatsApp, Linkedln and Twitter. The survey invitation contained information about the study and a link to a Google Form. The invitation was shared with the target participants through their social media accounts, and professional groups following approval from the group administrators. Participants could make comments, tag friends, and share the advertisement to their friends or Facebook profile page. The Google Form contained information about the study, consent to participate, and the survey link. In this study, consent was implied by completing the study. The recruitment was open for 30 days between February and March 2020.

\section{Procedure}

The online survey was designed and reported based on the Checklist for Reporting Results of Internet E-Surveys (CHERRIES), and guidelines for good practice in the conduct and reporting of online research. ${ }^{18}$ The survey link (Google Form ${ }^{\mathrm{TM}}$ ) contained three pages: Study information page, sociodemographic information page, and a questionnaire for assessing the prevalence of occupational violence towards pharmacists. Response to each question was voluntary, and for participants could decline to respond to some questions or provide information. Study participants were also able to review or change their responses, save inputs, and resume the survey later or voluntarily quit at any time. The following data were collected from the participants: Age, gender, years of experience, area of practice, information related to occupational violence, and recommendations.

\section{Measures}

The prevalence of occupational violence towards pharmacists was determined using a questionnaire that was adapted from previous studies. ${ }^{12-14}$ The draft questionnaire was presented to five experts on the subject matter and five target participants to test for face validity prior to the study. Feedback received regarding the wording, ease of understanding and relevant to study objectives was used to improve the questionnaire. The following domains were covered by the questionnaire: Nine questions about the aggressor and the violence incident; six questions about management, consequences, and reporting of violence; and one last open-ended question asking participants to recommend measure(s) to prevent occupational violence against pharmacists.

\section{Confidentiality and consent statement}

It was clearly stated in the first part of the online survey tool that participation is entirely voluntary, and respondents were able to skip any question they felt uncomfortable to answer. Moreover, they were assured of the confidentiality and anonymity of their response. Missing data was identified using missing response pattern, based on the recommendation of Hyun Kang (2013). ${ }^{19}$ Based on the sensitive nature of the study, data missing completely at random was included in the study.

Consent to participate in the study was clearly stated and was implied by clicking and submitting the online survey form. The study did not involve any specific institution, and it was considered a low risk; as such, ethical approval was not deemed necessary. Nevertheless, permission to share the questionnaire was sought from the leadership of the various specialties of pharmacy profession in Nigeria and from group administrators of some of the social media platforms.

\section{Operational definitions}

The following definitions were adopted in this study. ${ }^{14}$ Physical aggression was defined as forceful, hostile or aggressive behaviour which may or may not cause harm. A threat refers to the menace of causing harm. Verbal (nonphysical) aggression was defined as any annoying or unpleasant act (words, attitudes, actions) that creates a hostile working environment. Harassment was defined as insistent aggressive pressure or intimidation, requests, 
messages, phone calls or other unsolicited contact that may cause annoyance, worry, or fear.

\section{Data analysis}

Data cleaning, validation and analysis were performed using IBM SPSS Statistics for Windows, Version 25.0. Armonk, NY: IBM Corp. Responses were exported from the Google Form ${ }^{\mathrm{TM}}$ in Microsoft Excel format, and then transferred to the SPSS software. Descriptive statistics were conducted to determine the characteristics of the study sample. Data were presented as frequency and percentages. Differences in proportion among participants were analyzed using Chi-square or Fisher's exact test as appropriate. The prevalence of occupational violence towards pharmacists was estimated by dividing the number of participants that reported violence incident by the total number of the study sample. The completion rate of the survey was determined by dividing the number of participants who completed the survey by the total number of the participants. ${ }^{18}$ Age was re-coded based on the WHO age standardization. ${ }^{20}$ Responses to open-ended questions were analyzed by taking the proportion of common themes that came up repeatedly.

\section{RESULTS}

A total of 266 target participants clicked on the survey link between February 16 and March 15, 2020. Of this number, three did not attempt any question. A total of 263 participants started the survey, of which seven did not complete. Two-hundred and fifty-six participants completed the survey, with a completion rate of $99.2 \%$. Figure 1 illustrates the flowchart of the recruitment process. One hundred and eighty-nine respondents $(71.9 \%)$ were males, and $91(34.6 \%)$ of the respondents were in the age category of 31 to 35 years. Regarding years of experience, 135 (51.3\%) had six years and above; 189 (71.9\%) of the total participants were practicing in hospital pharmacies. Table 1 indicates the Sociodemographic characteristics of the study sample. Raw data available at: https://www.pharmacypractice.org/journal/index.php/pp/ article/view/2080/851

\begin{tabular}{|c|c|}
\hline Variables & Frequency (\%) \\
\hline \multicolumn{2}{|l|}{ Age category } \\
\hline$\leq 25$ years & $33(12.5)$ \\
\hline 26 to 30 & $91(34.6)$ \\
\hline 31 to 35 & $68(25.9)$ \\
\hline$\geq 36$ & $70(26.6)$ \\
\hline \multicolumn{2}{|l|}{ Gender } \\
\hline Male & 189 (71.9) \\
\hline Female & $73(27.8)$ \\
\hline \multicolumn{2}{|l|}{ Years of experience } \\
\hline$\leq$ Five years & $127(48.3)$ \\
\hline$\geq$ Six years & $135(51.3)$ \\
\hline \multicolumn{2}{|l|}{ Area of practice } \\
\hline Regulatory/administration & $12(4.6)$ \\
\hline Community pharmacy & $49(18.6)$ \\
\hline Hospital pharmacy & $189(71.9)$ \\
\hline
\end{tabular}

Two hundred and forty-three pharmacists reported violent events during professional practice, with a prevalence of $92.7 \%,(95 \% \mathrm{Cl}, 90$ to 96$)$. Sixty-eight (25.9\%) disclosed that the event happened while working alone. There was no statistically significant difference in prevalence of occupational violence in terms of age category (chi-square 2.077 (3); $p=0.557$ ); gender (chi-square 0.473 (1); $p=$ $0.557)$; years of experience (chi-square $1.769(1) ; p=0.184$ ); and area of practice (chi-square $0.793(2) ; p=0.673$ ). The prevalence was highest (66.2\%) among male pharmacists, and in those aged 26 to 30 years (32.7\%). Violent events occurred among $48.7 \%$ of pharmacists with six and above years of experience; and $68.4 \%$ of hospital pharmacists.

Pharmacists who participated in this study reported various forms of violent events related to verbal abuse (226, 95\%), physical aggression $(42,17.2 \%)$, and both verbal and physical abuse $(29,12.2 \%)$. There was no statistically significant difference in the proportion of verbal abuse and physical aggression among the subjects in terms of gender, age category, and years of practice experience. The prevalence of violence was significantly higher among participants practicing in hospital (77.4\%), compared with those practicing in regulatory/administration, and

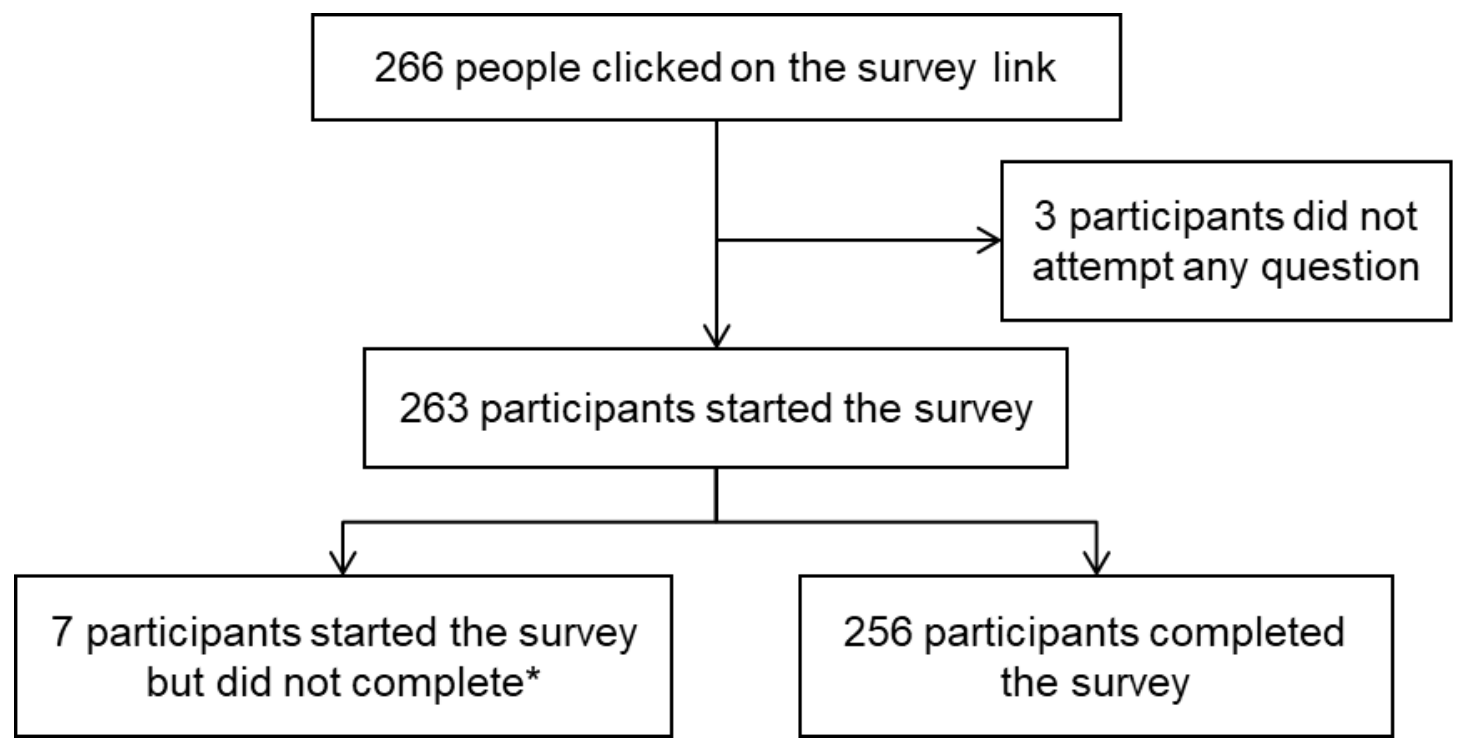

Figure 1. Flowchart of participants' recruitment process "stopped at questions asking, "have you ever experienced occupational violence?" 


\begin{tabular}{|c|c|c|c|c|c|}
\hline \multirow{2}{*}{ Variables } & \multirow{2}{*}{$\begin{array}{c}\text { Occupational violence } \\
n(\%)\end{array}$} & \multirow{2}{*}{ p-value ${ }^{1}$} & \multicolumn{3}{|c|}{ Type of violence } \\
\hline & & & Verbal abuse & Physical aggression & Both $^{2}$ \\
\hline \multicolumn{6}{|l|}{ Age category } \\
\hline$\leq 25$ years & $29(11.0)$ & 0.557 & $29(12.4)$ & $6(14.0)$ & $4(13.8)$ \\
\hline 26 to 30 & $86(32.7)$ & & $83(35.5)$ & 18 (41.9) & $13(44.8)$ \\
\hline 31 to 35 & $62(23.6)$ & & $61(26.1)$ & $8(18.6)$ & $6(20.7)$ \\
\hline$\geq 36$ & $66(25.1)$ & & $61(26.1)$ & $11(25.6)$ & $6(20.7)$ \\
\hline \multicolumn{6}{|l|}{ Gender } \\
\hline Male & $174(66.2)$ & 0.492 & $169(72.2)$ & $31(72.1)$ & $20(69.0)$ \\
\hline Female & 69 (26.2) & & $65(27.8)$ & $12(27.9)$ & $9(31.0)$ \\
\hline \multicolumn{6}{|l|}{ Years of experience } \\
\hline$\leq 5$ years & $115(43.7)$ & 0.184 & $116(49.6)$ & $22(51.2)$ & $17(58.6)$ \\
\hline$\geq 6$ years & $128(48.7)$ & & $118(50.4)$ & $21(48.8)$ & $12(41.4)$ \\
\hline \multicolumn{6}{|l|}{ Area of practice } \\
\hline Regulatory/administration & $12(4.6)$ & 0.673 & $11(4.8)$ & $6(14.3)$ & $5(17.2)$ \\
\hline Community pharmacy & 46 (17.5) & & $41(17.8)$ & $9(21.4)$ & $5(17.2)$ \\
\hline Hospital pharmacy & $180(68.4)$ & & $178(7.4)$ & $27(64.3)$ & $19(65.5)$ \\
\hline
\end{tabular}

community pharmacy, (chi-square 10.213 (2); $p=0.006$ ). Similarly, the rate of physical aggression was significantly higher towards pharmacists working in hospital pharmacy $(64.3 \%)$ than those in the community pharmacy and regulatory/administration (chi-square 10.646 (2), p=0.005). With regards to the actions taken by the participants at the time of the violent incidents, 45 (18.8\%) called for help, and $194(81.2 \%)$ handled the events by themselves. The prevalence and types of occupational violence are shown in Table 2.

Three broad categories of aggressors were identified: Coworkers, patients, and patients' caregivers. The co-workers included fellow pharmacists (10.6\%), doctors (27.0\%), pharmacy technicians (5.7\%), nurses (14.4\%) and administration staff (17.9\%). There was no statistically significant difference in proportion among these categories of aggressors with regards to gender. The majority of the aggressors (73\%) were patients, with a significantly higher proportion of them being males. Patients' caregivers accounted for $46.8 \%$, with a significantly higher percentage of males than females (Table 3 ).

Of the total respondents, $34.6 \%$ encountered violent events from one category of aggressors; $30 \%$ from two; $14.1 \%$ from three; and $21.3 \%$ from four categories and above.

The participants reported different factors that led to the violent incident. The common factors included frustration due to long queue $(96,36.5 \%)$, refusal to fulfil aggressor's demand $(58,22.1)$, during counselling/poor communication $(57,21.7)$, during enforcement by regulatory bodies $(5$, $1.9)$, and financial constraint $(4,1.5 \%)$.
Among the participants who experienced violence, 118 $(48.6 \%)$ reported the incident to superior personnel; 20 $(7.6 \%)$ to a superior co-worker, $230(87.4 \%)$ to the head of department/unit/management, and $18(6.8 \%)$ to the police. In instances where violence was reported, an action was taken in 105 (39.9\%) events, and 75 (28.5\%) of the aggrieved respondents disclosed that they were satisfied with the action(s) taken. Table 4 illustrates the frequency of reporting occupational violence by the respondents.

Table 5 shows various strategies recommended by the participants to reduce the occurrences of a violent incident in practice settings. Most (23\%) respondents suggested an improved awareness on pharmacist's role among patients and co-workers, $18 \%$ recommended that more pharmacists should be employed to reduce the patient waiting time, and $14 \%$ submitted that there should be strict penalties against the perpetrators to serve as deterrent or lesson to others.

\section{DISCUSSION}

This study presents the first data on occupational violence exclusively faced by pharmacists in Nigeria, and in SubSaharan Africa, to the best of our knowledge. The study reveals a high prevalence of occupational violence (92.7\%) towards pharmacists in Nigeria, and further highlights factors related to the violence and recommendations for interventions. There were limited studies on occupational violence towards pharmacists in the literature to allow comparison. However, the prevalence rate determined in the current study was similar to the rate reported among community pharmacy practitioners in Australia, but higher

\begin{tabular}{|c|c|c|c|c|}
\hline \multirow{2}{*}{ Categories of aggressors } & \multicolumn{3}{|c|}{ Frequency (\%) } & \multirow{2}{*}{ p-value ${ }^{1}$} \\
\hline & Total & Male & Female & \\
\hline \multicolumn{5}{|l|}{ Co-workers } \\
\hline Pharmacist & $28(10.6)$ & $18(64.3)$ & $10(35.7)$ & 0.272 \\
\hline Doctor & $71(27.0)$ & $57(80.3)$ & $14(19.7)$ & 0.031 \\
\hline Pharmacy Technician & $15(5.7)$ & $10(66.7)$ & $5(33.3)$ & 0.588 \\
\hline Nurse & $38(14.4)$ & $22(57.9)$ & $16(42.1)$ & 0.138 \\
\hline Admin staff & $47(17.9)$ & $37(78.7)$ & $10(21.3)$ & 0.115 \\
\hline Patients & $192(73.0)$ & $137(71.4)$ & $59(30.7)$ & $<0.001$ \\
\hline Patient's caregiver & $123(46.8)$ & $91(74.0)$ & $31(25.2)$ & 0.010 \\
\hline Others $^{2}$ & $22(8.4)$ & $16(72.7)$ & $6(27.3)$ & 0.534 \\
\hline
\end{tabular}




\begin{tabular}{|c|c|c|c|c|c|c|}
\hline \multirow{2}{*}{ Type of violence } & \multirow{2}{*}{$\begin{array}{l}\text { Reported } \\
\text { (Yes) }\end{array}$} & \multicolumn{3}{|c|}{$\begin{array}{c}\text { Personnel where violence } \\
\text { was reported }\end{array}$} & \multirow{2}{*}{$\begin{array}{l}\text { Action was taken } \\
\text { (Yes) }\end{array}$} & \multirow{2}{*}{$\begin{array}{l}\text { Satisfaction } \\
\text { (Yes) }\end{array}$} \\
\hline & & Superior co-worker & HOD & Police & & \\
\hline Verbal abuse & $108(47.0)$ & $9(8.0)$ & $98(87.5)$ & $5(4.5)$ & $43(26.2)$ & $31(31.6)$ \\
\hline Physical aggression & $29(67.4)$ & $2(5.9)$ & $26(76.5)$ & $6(17.6)$ & $13(32.5)$ & $8(38.1)$ \\
\hline Physical aggression and verbal abuse & $116(47.5)$ & $9(7.4)$ & $106(86.9)$ & $7(5.7)$ & $49(27.7)$ & $36(21.9)$ \\
\hline
\end{tabular}

*Total percentage may add up to more than $100 \%$ as multiple responses were allowed; HOD, head of department/unit/management

than obtained in a related study in Ireland. $^{15,16}$ The difference in the prevalence of violence may be due to the variation in the definition of violence, type of health care workers targeted, and the methodology employed. Although violence occurs in all work environments, certain economic sectors are particularly more predisposed to violence, such as the health related social services sector. It was reported that healthcare workers face about eight times the risk of violence from patients/clients than other service workers. $^{21}$

The current study showed that pharmacists aged 30 years and below reported more violence when compared with other age categories. In a related study in Turkey, the risk of violence was 2.4 times higher among healthcare workers aged less than 30 years old than among older ones; however, the years of experience did not constitute a significant risk factor for violence. ${ }^{22}$

The majority of the pharmacists that experienced violence had six and above years of experience, although there is no significant difference compared to respondents with less than six years of experience. However, in an Ethiopian study, Yenealem et al., demonstrated that healthcare workers with less than six years of experience were three times more likely to have experienced violence than their seniors with more than 16 years of experience. ${ }^{23}$ The finding was explained by the fact that young healthcare workers with short duration of experience lack the skills required to manage violent tendencies, which are usually acquired through experiences. Furthermore, two studies in Riyadh, Kingdom of Saudi Arabia (KSA), showed that less experienced and younger healthcare workers were more likely to encounter violent attacks than their counterparts. ${ }^{24,25}$

In regard to the types of violence, the present study showed that the most frequent type of violence was verbal abuse. Earlier studies conducted in KSA reported similar findings; Algwaiz and Alghanim (88.8\% verbal and $1.6 \%$ physical) and Al-turki et al., (94.3\% verbal and $6.5 \%$ physical). ${ }^{22,25}$ Verbal abuse is more frequently reported than other attacks and is mostly directed towards pharmacists in the hospital setting, probably because it is the initial phase for subsequent physical violence. The prevalence of violence is highest towards hospital pharmacists in this study. This might be explained by the substantially low pharmacist-to-patient ratio in Nigerian public hospitals, resulting in longer patient waiting time in the hospital pharmacy units and dissatisfaction. ${ }^{8}$ Since hospital pharmacists represent about two-thirds (68.4\%) of the total respondents in this study, generalization of these findings should be treated with caution.

In consistence with previous findings, this study revealed that patients are the most frequent aggressors towards pharmacists, followed by patients' relatives. ${ }^{26,27}$ When patients are in pain and had to wait for a long time to be seen by a physician or to receive medications, they and their relatives may feel stressed, angry or frustrated, thus, becoming more likely to commit violence against others, such as healthcare providers. ${ }^{25,28}$ This further explains why pharmacists reported in this study that the most frequent factor associated with aggression towards them is frustration due to long waiting time (36.5\%).

It was shown that healthcare workers may be responsible for emotional, verbal, and physical abuse against each other. ${ }^{29}$ This study revealed that co-workers also commit violence towards pharmacists, with doctors being the most reported group (Table 3). Ideally, hospitals should be free from violence, especially between colleagues, and healthcare staff should work in a cooperative manner to provide a safe environment for both the patients and themselves.

In the present study, more than half of the respondents who experienced verbal abuse (53\%) and both verbal and physical aggression (52.5\%) never reported it, and unfortunately, no action was taken in the majority of the reported cases. Many findings have shown that workplace violence is under-reported. ${ }^{26,27}$ This might be a result of oppressed behavior, as many healthcare workers accept verbal abuse from all sources as part of their job and do not believe that they have the power to prevent such events. ${ }^{30}$ In addition, being accustomed to workplace violence is the most stated reason for healthcare workers not reporting violence to the hospital administration or the authorities. ${ }^{29}$

Several strategies were recommended by the respondents on how to reduce the occurrences of violent incidents in practice settings (Table 5). These included improving awareness on pharmacists' roles among patients and coworkers, increasing pharmacists' workforce to reduce patient waiting time, improving inter-professional harmony, and training workers on violence risk assessment and management. Studies have shown that continuing

\begin{tabular}{|l|c|}
\hline \multicolumn{1}{|c|}{ Table 5. Strategies to prevent/reduce occupational violence towards pharmacists recommended by the survey participants ( $\mathrm{n}=263$ ) } \\
\hline \multicolumn{1}{|c|}{ Percentage } \\
\hline Improved awareness on pharmacist's role among patients and co-workers & $23 \%$ \\
\hline More pharmacists to reduce patient waiting time & $18 \%$ \\
\hline Improved interprofessional harmony & $18 \%$ \\
\hline Training on workplace violence risk assessment and management & $17 \%$ \\
\hline Strict penalties for perpetrators & $14 \%$ \\
\hline Provision of security personnel/physical barrier & $10 \%$ \\
\hline
\end{tabular}


pharmacy professional development is necessary to improve the pharmacists' confidence in providing medication-related advice. ${ }^{31}$ Such trainings can support the development of procedural and conceptual knowledge in a local environment to support learning and innovation, which in turn will improve communication between pharmacists and patients or patient's relatives. ${ }^{32}$

\section{Strengths and limitations of the study}

This study provides a baseline for understanding workplace violence towards pharmacists in Nigeria, which can be extended to other developing countries. Secondly, several preventive measures were recommended. These recommendations could guide the development and implementation of preventive interventions. Moreover, the study demonstrates that occupational violence towards pharmacists can be resolved by a superior pharmacist in the practice settings. Finally, findings from this study present preliminary data that could guide policy directions in reducing incidents of occupational violence in Nigeria.

The study has some limitations. First, the use of an online survey in the recruitment of participants may automatically exclude many potential participants who do not use social media platforms. As such, the findings may not be generalizable to all pharmacists in Nigeria. Secondly, a violence event involves two parties, aggressor and oppressed. However, the information reported here is only from the oppressed party, with no aggressors' perspective. The one-sided inquiry nature employed could also introduce information bias, thus, caution is suggested in the interpretation and application of these results.

\section{CONCLUSIONS}

Findings from this study demonstrate a high prevalence of occupational violence towards pharmacists in Nigeria, which could have undesirable consequences. Moreover, pharmacists practicing in the hospital settings are at highest risk of these violent incidents. Broad categories of perpetrators have been identified, including patients, patients' caregivers, and co-workers. Commonly-reported factors associated with the violence included frustrations due to long waiting time at the pharmacy, refusal to fulfil aggressor's demands due to ethical boundaries, and poor communication, which is often related to language barriers. Therefore, interventions such as improving awareness regarding the role of pharmacists in healthcare settings, engaging more pharmacists in practice areas by increasing pharmacists' workforce to alleviate longer waiting times, interprofessional harmony, staff training on violence risk assessment and management, and provision of strict penalties to offenders could prevent the rising incidents of occupational violence towards pharmacists not only in Nigeria, but globally. Finally, professional organizations such as the International Pharmaceutical Federation (FIP) should develop means of expanding this kind of study in order to find the global trends on occupational violence towards pharmacists, and to develop guidance, working documents, or advocacy strategies for its members on how to mitigate occupational violence.

\section{ACKNOWLEDGEMENTS}

The authors would like to thank writing consultant Katherine Randazzo, at the University of lowa Writing Center, lowa City, IA (USA), for the thoughtful English language writing consultancy service. Also, important, the authors thank the participants.

\section{CONFLICT OF INTEREST}

None to declare.

\section{FUNDING}

This research did not receive any specific grant from funding agencies in the public, commercial, or not-forprofit sectors.

References

1. International Pharmaceutical Federation (FIP): Pharmacists supporting women and responsible use of medicines: Empowering informal caregivers. Available at: https://www.fip.org/files/fip/publications/Pharmacists-supporting-womenresponsible-use-medicines.pdf (accessed Jan 23, 2020).

2. International Pharmaceutical Federation (FIP): Strategic Plan2019 to 2024. Available at: https://www.fip.org/file/4369 (accessed Jan 23, 2020).

3. Uzman N, Williams AE, Altiere RJ, Anderson C, Bates I. Implementing FIP's global pharmaceutical education transformation vision in Sub-Saharan African Countries. Res Soc Adm Pharm. 2020;16(8):1131-1135: https://doi.org/10.1016/j.sapharm.2019.12.011

4. Abubakar AR, Chedi BAZ, Mohammed KG, Haque M. Drug interaction and its implication in clinical practice and personalized medicine. Natl. J. Physiol. Pharm. Pharmacol. 2015;5(5):345-349. https://doi.org/10.5455/njppp.2015.5.2005201557

5. Jatau AI, Shitu Z, Khalid GM, Yunusa I, Awaisu A. Understanding adverse drug-related emergency department visits: development of a conceptual model through a systematic review. Ther Adv Drug Saf. 2019;10:1-18. https://doi.org/10.1177/2042098619852552

6. Khalid GM, Jatau AI, Ibrahim UI, Dungus FM, Shity Z, Sha'aban A, Burji SL. Antibiotics self-medication among undergraduate pharmacy students in Northern Nigeria. Med Access Point Care. 2019;1-18. https://doi.org/10.1177/2399202619846847

7. Federal Bureau of Statistics of Nigeria, National Population Commission. National Population Estimates 2006-2016. Available at: http://nigerianstat.gov.ng/elibrary (assessed Sep 17, 2020).

8. Ekpenyong A, Udoh A, Kpokiri E, Bates I. An analysis of pharmacy workforce capacity in Nigeria. J Pharm Policy Pract. 2018;11:20. https://doi.org/10.1186/s40545-018-0147-9 
9. World Health Organization (WHO): Density of pharmacists (total number per 10000 population, latest available year). Available at: https://www.who.int/gho/health workforce/pharmacists density/en/ (assessed Sep 17, 2020).

10. World Health Organization (WHO): Violence against health workers. Available at: https://www.who.int/violence injury prevention/violence/workplace/en/ (accessed Jan 23, 2020).

11. Peek-Asa C, Howard J, Vargas L, Kraus JF. Incidence of non-fatal workplace assault injuries determined from employer's reports in California. J Occup Environ Med. 1997;39(1):44-50. https://doi.org/10.1097/00043764-199701000-00009

12. Pompeii LA, Schoenfisch AL, Lipscomb HJ, Dement JM, Smith CD, Upadhyaya M. Physical assault, physical threat, and verbal abuse perpetrated against hospital workers by patients or visitors in six U.S. hospitals. Am J Ind Med. 2015;58(11):1194-1204. https://doi.org/10.1002/ajim.22489

13. Ferri $P$, Silvestri M, Artoni $C$, Di Lorenzo R. Workplace violence in different settings and among various health professionals in an Italian general hospital: a cross-sectional study. Psychol Res Behav Manag. 2016;9:263-275 Published 2016 Sep 23. https://doi.org/10.2147/prbm.s114870

14. Magnavita N, Heponiemi T. Violence towards health care workers in a Public Health Care Facility in Italy: a repeated cross-sectional study. BMC Health Serv Res. 2012;12:108. https://doi.org/10.1186/1472-6963-12-108

15. FitzGerald D, Reid A. Frequency and consequences of violence in community pharmacies in Ireland. Occup Med (Lond). 2012;62(8):632-637. https://doi.org/10.1093/occmed//kqs154

16. Peterson GM, Tan SI, Jackson SL, Naunton M. Violence in community pharmacy in Australia: incidence and implications. Int J Clin Pharm. 2011;33(2):264-272. https://doi.org/10.1007/s11096-011-9492-3

17. Naing L, Winn T, Rusli B. Practical issues in calculating the sample size for prevalence studies. Arch Orofacial Sci. 2006;1:9-14.

18. Eysenbach G. Improving the quality of Web surveys: the Checklist for Reporting Results of Internet E-Surveys (CHERRIES) [published correction appears in doi:10.2196/jmir.2042]. J Med Internet Res. 2004;6(3):e34. https://doi.org/10.2196/imir.6.3.e34

19. Kang $\mathrm{H}$. The prevention and handling of the missing data. Korean J Anesthesiol. 2013;64(5):402-406. https://doi.org/10.4097/kjae.2013.64.5.402

20. Ahmad OB, Boschi-Pinto C, Lopez AD, Murray CJL, Lozano R, Inoue M. Age standardization of rates: a new WHO standard. Geneva: WHO 2001.

21. Nelson R. Tackling violence against health-care workers. Lancet. 2014;383(9926):1373-1374. https://doi.org/10.1016/s0140-6736(14)60658-9

22. Al-Turki N, Afify AA, AIAteeq M. Violence against health workers in Family Medicine Centers. J Multidiscip Healthc. 2016;9:257-266. https://doi.org/10.2147/jmdh.s105407

23. Yenealem DG, Woldegebriel MK, Olana AT, Mekonnen TH. Violence at work: determinants \& prevalence among health care workers, northwest Ethiopia: an institutional based cross sectional study. Ann Occup Environ Med. 2019;31:8. https://doi.org/10.1186/s40557-019-0288-6

24. Alharthy N, Mutairi MA, Alsahli A, Alshehri A, Almatrafi A, Mahah A, Alswailem AK, Phiulip W, Qureshi S. Workplace violence among emergency medical services workers in Riyadh, Saudi Arabia. J Hosp Adm. 2017;6(3):26-32. https://doi.org/10.5430/jha.v6n3p26

25. Algwaiz WM, Alghanim SA. Violence exposure among health care professionals in Saudi public hospitals. A preliminary investigation. Saudi Med J. 2012;33(1):76-82.

26. Samir N, Mohamed R, Moustafa E, Abou Saif H. Nurses' attitudes and reactions to workplace violence in obstetrics and gynaecology departments in Cairo hospitals. East Mediterr Health J. 2012;18(3):198-204 https://doi.org/10.26719/2012.18.3.198

27. Talas MS, Kocaöz S, Akgüç S. A survey of violence against staff working in the emergency department in ankara, Turkey. Asian Nurs Res (Korean Soc Nurs Sci). 2011;5(4):197-203. https://doi.org/10.1016/i.anr.2011.11.001

28. Behnam M, Tillotson RD, Davis SM, Hobbs GR. Violence in the emergency department: a national survey of emergency medicine residents and attending physicians. J Emerg Med. 2011;40(5):565-579. https://doi.org/10.1016/j.jemermed.2009.11.007

29. Hajaj AM. Violence against nurses in the workplace. Middle East J Nurs. 2014;7(3):20-26.

30. Hogarth KM, Beattie J, Morphet J. Nurses' attitudes towards the reporting of violence in the emergency department. Australas Emerg Nurs J. 2016;19(2):75-81. https://doi.org/10.1016/i.aenj.2015.03.006

31. Yee KC, De Marco M, Salahudeen MS, Peterson GM, Thomas J, Naunton M, Kosari S. Pharmacists as a source of advice on medication use for athletes. Pharmacy. 2020;8:10. https://doi.org/10.3390/pharmacy8010010

32. Steenhof N. Adaptive expertise in continuing pharmacy professional development. Pharmacy. 2020;8:1-6. https://doi.org/10.3390/pharmacy8010021 